\title{
Lack of antibiotic knowledge and misuse of antibiotics by medical students in Mali: A cross-sectional study
}

\begin{abstract}
Background and aims: Misuse of antibiotics, especially in low-and-middle-income countries is a major contributor to antimicrobial resistance. Medical students are antibiotic consumers and prescribers in the future. This study aimed to assess antibiotic knowledge and utilization among medical students in the Republic of Mali, and to determine the relationship between knowledge and health-seeking behavior in relation to antibiotic use.

Methods: A cross-sectional survey was conducted in the only public medical university in Mali. The questionnaire explored knowledge about antibiotics of medical students, and health behaviors for self-limiting illness. Data were analyzed in SPSS.

Results: A total of 446 medical students completed the questionnaire. The average knowledge score was 4.12 out of 10. Students with clinical experience performed higher (4.79 vs 3.74, $p<0.01) ; 391(87.7 \%)$ medical students reported experience of self-limiting diseases in the past year. Of these $197(50.4 \%)$ went to see a doctor, $160(81.2 \%)$ of whom were prescribed antibiotics: 151 medical students self-treated, with 121(80.1\%) using antibiotics.

Conclusion: This study shows poor knowledge and massive misuse of antibiotics among medical students in Mali. Promoting education on the mechanism of antibiotics, antimicrobial resistance and rational antibiotic use among medical students should be a priority in the medical school curriculum.
\end{abstract}

Key words: Antibiotics; Antimicrobial resistance; Mali; Medical students; Knowledge; Crosssectional study 


\section{Introduction}

Misuse of antibiotics, both in medicine and agriculture, is well-established as the major driver of antimicrobial resistance (AMR). AMR is known to be a serious problem for developed and developing countries, rural and urban areas, human beings and animals, [1, 2]. Unless effective control measures are introduced, mortality attributable to AMR is predicted to rise from 700,000 in 2015 , to as high as 10 million by 2050 . Nearly half of that mortality, an estimated 4.2 million deaths, are expected to occur in Africa [3]. A recent study across 76 countries reported a 65\% increase in antibiotic use between 2000 and 2015. Most of this increase happened in low- and middle-income countries (LMICs), where it was correlated with growth in per capita Gross Domestic Product [4]. Access to antibiotics in these countries is increased through very poor or non-existent antibiotic stewardship; around half of antibiotics are purchased from pharmacies, market stalls or street vendors [5]. This leads to large quantities of antibiotics consumed and in circulation, which contributes considerably to AMR. Based on the current trajectory, global antibiotic consumption will double between 2015 and 2030 [4]. Reducing global consumption is thus crucial to reducing the threat of AMR [6] and reducing its global economic impact, estimated at a loss of $\$ 100$ trillion by 2050 [3].

The COVID-19 pandemic had led to an increase in antibiotic use in many countries The lack of specific treatments for the illness and the need for antibiotics to control secondary bacterial infections have led to an increase in antibiotic use. Although secondary infection in patients with COVID-19 is relatively low, the reported antimicrobial prescribing is high [7, 8]. As a consequence, the global threat of AMR has increased, with the potential emergence and spread of antibiotic-resistant pathogens $[9,10]$. Doctors contribute to AMR through overprescribing of antibiotics. This occurs for a variety of reasons. First, there is demand from patients [11]. Many patients believe that antibiotics are effective against common selflimiting illnesses, and they are unaware of the phenomenon of antibiotic resistance and its consequences [12]. Second, many doctors lack adequate training in rational prescribing. An inverse correlation has been found between such training and unnecessary antibiotic prescription [13]. Few Sub-Saharan African countries have active antibiotic stewardship programs (ASPs). A survey in Nigeria reported that only $24 \%$ of the tertiary facilities had an ASP and only $36.5 \%$ of the medical staffs knew about ASP in Nigeria $[14,15]$. Third, guidelines for antibiotic prescribing, where they exist, are often not followed [16]. Forth, pharmaceutical companies try to influence prescribing of antibiotics through promoting their products, among doctors often with attractive incentives [17].

In most of LMICs, s there is lack of awareness of AMR and AMS [18, 19], specific training in rational prescribing is poor and there is little or no evaluation of medical students' prescribing skills as a prerequisite for professional qualification [20]. For example, most physicians (92\%) and pharmacists (86\%) had never undertaken AMS training in Zambia [21]. Only 37.7\% of the 
final year pharmacy students had AMS training in South Africa [22] and only 33\% were confident to prescribe antibiotics [23]. A major challenge is that antibiotics are much more likely to be indicated in primary care settings in LMIC, especially in Sub-Sharan Africa, because of higher circulating levels of bacterial infection, for example, pneumonia, meningitis, and dysentery [24]. In addition, access to diagnostics is limited, making differentiation between bacterial and viral infections often impossible, and the default is to prescribe antibiotics [25]. In Africa, few countries carry out surveillance of drug resistance, so the true extent of the AMR problem is unknown [26]. Although some African countries have launched action plans or regulations on AMR like Eswatini, Nigeria and Namibia [27-29], Mali does not yet have an ASP or a national action plan on AMR.

This research was carried-out in Mali, West Africa. There are no published studies on the knowledge, attitudes and practice towards antibiotics in the Republic of Mali. The population of Mali was 20.34 million in 2020, and it is expected to double in the next 20 years because of the high fertility rate at 6.2 children per woman of reproductive age. It was a French colony and gained independence in 1960 [30]. In 2019, Mali ranked 184th out of 189 countries in the Human Development Index and $49.7 \%$ of the population are categorized as living in poverty.

This study was conducted among students at the only public medical school in Mali [31]. These students are future medical professionals, represent the educational elite, and are future opinion leaders. In addition, they are potential consumers of antibiotics themselves. This study aims (i) to assess antibiotic knowledge and utilization among medical students in the Republic of Mali; (ii) to determine the association between knowledge and health-seeking behavior in relation to antibiotic use.

\section{Methods}

\subsection{Study design}

We carried out a cross-sectional survey using a self-completion questionnaire among medical students in July to August 2019.

\subsection{Study participants}

All study participants came from the only public medical university in the country, the University of Sciences, Techniques and Technology of Bamako (USTTB) [32]. The medical school curriculum lasts seven years. Students are trained in the classroom setting in the first two years and have exposure to patients from Year 3. Around 1,200 students are admitted to medical school. A high failure rate in end-of-year exams leads to a dramatic fall in numbers of attending students, with less than 300 graduating.

\subsection{Questionnaire}

The questionnaire drew on tools used elsewhere incuding Sri Lanka [32], Egypt [33] and China [34,35] . It included the following areas: (1) sociodemographic information, (2) antibiotic knowledge, (3) healthcare-seeking behaviours for self-limiting illness in the past year.

The questionnaire, was translated from English into French by two Masters students, and was modified by two Malian professors. 


\subsection{Data collection}

With help from local research assistants, questionnaires were distributed among medical students after they finished the final end-of-year exams. This timing helped to maximize uptake, since attendance at exams was high. We explained the purpose and procedures of the project to the students individually, and obtained oral consent before the data collection. We observed the completion of the questionnaires to prevent sharing of answers.

\subsection{Data Analysis}

All the data were double-entered by two research assistants. The knowledge score for each participant was the sum of correct answers for the 10 knowledge questions. These were then dichotomized to low (0-4) and high (5-10) level groups. Analysis was conducted using SPSS Version v.24.0. We used the Pearson Chi-squared test and Fisher-Exact Test to compare the differences in antibiotic use behaviors between which groups.

\subsection{Ethical approval and consent to participants}

Ethical approvals were acquired for this study from: (1) University of Science, Technologies and Technique of Bamako (USTTB), Code of Research: N²019/97/CE/FMPOS; (2) the Institutional Ethical Clearance Committee, Zhejiang University School of Public Health, Code of Research: ZGL201906-2.

\section{Results}

\subsection{Sociodemographic characteristics (Table 1)}

Of the 500 distributed questionnaires we collected 446 , a response rate of $89.2 \%$. We excluded $54(10.8 \%)$ questionnaires because of the lack of completion of key variables. Over two-thirds of respondents were male ( $69.5 \%$ vs $30.5 \%$ females) reflecting the sex ratio in the school. The average age of participants was $21.3 \pm 2.4$ years. The overwhelming majority, $406(90.6 \%)$ were single; $292(65.5 \%)$ of the students came from urban areas and $164(34.5 \%)$ students were from rural areas. Nearly two-thirds $290(65.0 \%)$ of the students were from families with incomes less than 100,000 FCFA (US\$169) per month, and only 42 (9.4\%) from families were more than 500,000 FCFA (US\$844) per month; Most of the students 398 (89.2\%) self-identified as Muslim and $46(10.3 \%)$ were Christians.

\subsection{Knowledge of antibiotic use (Table 2)}

The mean knowledge score was 4.12. Students with some clinical experience scored better than those without (4.79 vs 3.74, $p<0.01)$. The knowledge component of the questionnaire comprised three parts: knowledge of antibiotic use, knowledge and attitudes to antimicrobial resistance and antibiotic safety. In terms of antibiotic use a minority of students correctly answered that antibiotics did not work for viral infections, flu, sore throat, and common diarrhea (39.9\%, 32.1\%, 19.7\%, 27.1\%, respectively). 321 (72\%) falsely believed that newer antibiotics were always more effective than old ones, and 193 (43.3\%) students thought that infusion is the best way to give antibiotics. In relation to antimicrobial resistance, 275 (61.7\%) medical students recognized that overuse of antibiotics would lead to difficulties in treating bacterial 
infections, and 257 (57.6\%) of the participants agreed that incorrect use of antibiotics would result in fewer antibiotics we could use. Only 233 (52.2\%) of the medical students knew that antibiotics might cause allergy leading to death.

\subsection{Healthcare-seeking behavior and antibiotic use (Fig. 1)}

Among the 446 medical students, 391 (87.7\%) of them reported that they had experienced a self-limiting illness in the past year. Of these 197 (50.4\%) went to see a doctor, 151 (38.6\%) treated themselves and $43(11.0 \%)$ did nothing. Of the 197 medical students who went to see a doctor, 160 (81.2\%) were prescribed antibiotics, of which 36 (22.5\%) were given by infusion. Of the 151 medical students who self-treated, 121(80.1\%) used antibiotics and $86(71.1 \%)$ of them got the antibiotics without prescription. Of particular note, $10(8.2 \%)$ students who selftreated used antibiotic infusion, available in pharmacies. In addition, $272(61.0 \%)$ medical students kept a stock of antibiotics at home or in the dormitory.

\subsection{Determinants of antibiotic use (Table 3)}

A number of determinants of knowledge and behaviors emerged. The most marked differences were in grades between senior and junior medical students (with or without clinical exposure). Compared with junior students, senior students were more likely to treat themselves $(50.7 \% \mathrm{vs}$ $31.7 \%, p<0.001$ ) while junior students with self-limiting diseases were more likely to see a doctor $(58.2 \%$ vs $36.6 \%, p<0.01)$. Among students who chose to see a doctor, senior students were more likely to be prescribed with antibiotics $(96.2 \%$ vs $75.9 \%, p<0.001)$. Students from high income families were more likely to self-treat than those from middle and low income families $(56.8 \%, 35.0 \%, 37.5 \%$, respectively, $p=0.053)$. There were no significant differences in antibiotic use across gender, marital status and hometown (urban or rural). In addition, higher knowledge level of antibiotics did not influence: antibiotic storage ( $60.6 \%$ vs $61.2 \%, p=0.90)$, seeing a doctor $(49.1 \%$ vs $51.3 \%, p=0.66)$, being prescribed with antibiotics $(83.8 \%$ vs $79.5 \%$, $p=0.45$ ), self-treatment ( $39.9 \%$ vs $37.7 \%, p=0.67)$ self-treatment with antibiotics $(75.4 \%$ vs $83.7 \%, p=0.20)$. and antibiotic storage ( $60.6 \%$ vs $61.2 \%, p=0.90)$, Moreover, after adjusting for age, sex, religion, hometown, family income and grade, a higher level of antibiotic knowledge did not influence antibiotic use behavior.

\section{Discussion}

To our knowledge, this is the first survey about antibiotic use among university students in Mali. We show low levels of knowledge and overuse of antibiotics among Malian medical students who are part of the highly educated elite. The average score out of 10 true-or-false questions for antibiotics was only 4.12. Students with more years of medical training scored higher, but overall scores were low across all grades. Interestingly students seemed to be relatively knowledgeable about the threat of AMR, but don't make the link with personal overuse of antibiotics. In terms of behavior, over three-quarters (78\%) used antibiotics for treating self-limiting illness and over half $(61.0 \%)$ stored antibiotics at home. 
But Malian medical students are far from unique in this regard. A study in South Africa shows that a relatively low percentage of medical students had confident knowledge about antibiotics [23]..A study in Malaysia also found most of the university medical students know little about antibiotic usage, [36]. As for behavior, similar results are found that a total of thirty four studies in developing countries shows the overall rate of antimicrobial self-medication among adult individuals was $38.8 \%$, with relatively high levels in Ethiopia at 86\%, with antibiotics mostly sourced at pharmacies [37]. Another study found that misuse of antibiotics through self-medication is common among students in Accra, the capital of Ghana, whose prevalence of self-medication was $70 \%$ [38].

We found that students with more medical training were more likely to self-treat with antibiotics and be prescribed with antibiotics. While apparently counter-intuitive, this may be because these students have the training and confidence to self-treat, or to demand antibiotics from a doctor. A study from France had similar findings [39]. We found that $22.5 \%$ of the students prescribed with antibiotics by doctors received infusions and $8.2 \%$ of those who selftreated with antibiotics also used intramuscular injection Cases of self-injection with antibiotics for treating self-limited diseases are very rarely reported in any other countries.

The level of knowledge measured in our study shows no significant relationship with antibiotic misuse. A former study reported that the relationship between knowledge and behavior is not straightforward [39]. If knowledge does not influence behavior it is important to understand what influences antibiotic misuse and what drives the $80 \%$ use of antibiotic for self-limiting illness. First, a relatively high incidence of bacterial infection means that antibiotics are more likely to be indicated and may be life-saving. However, by self-limiting we are referring to conditions like the common cold and uncomplicated diarrhea, which medical students should recognize as not requiring antibiotics. Second, antibiotics are very available in retail pharmacies, even in markets, easily purchased, and stored at home, as was common among our respondents. Widespread use is a cultural norm, leading to antibiotics being referred to as "peanuts" [40].

Our findings help to inform measures which can be taken to address the problem of overuse of antibiotics. All key stakeholder groups should be involved, including patients, medical students, pharmacists, medical staff, policy-makers and hospital management [41].

First, with self-medication very common, it is clear that addressing the demand side is key. [42]. Health promotion campaigns, with simple clear messaging need to be carried-out among the general public. Mass media and social media can also play a role in arousing people's awareness of AMR. In addition, education about antibiotics and AMR should be incorporated into the school curriculum

Second, the quality of medical education should be improved in Mali. Although lack of knowledge is recognized as an independent risk factor for antibiotic misuse [34, 35], we did not find this. Unexpectedly, according to our survey, senior students who got higher scores in our antibiotic knowledge test were more likely to self-medicate with antibiotics. We 
recommend that medical students are provided with information to give them a better understanding of the personal relevance of the adverse consequences of antibiotic abuse.

Third, the supply side is also important. On the one hand, medical workers need to improve their knowledge of antibiotics. Research from Sweden shows that feedback on prescribing, that is checking of prescriptions, and continuous education together with behavioural change interventions are needed to reduce irrational antibiotic prescribing [43].Another study in China also suggests that improved education on rational prescribing guidelines is important. In addition, the tensions in the doctor-patient relationship also effects doctors' behavior of antibiotic prescribing [34]., Pharmacists should also receive more training and education. Community pharmacists are often the first points of contact for patients in many settings. So, their knowledge and behavior are key to achieving the goal of reducing antibiotic misuse. Ideally, they should sell antibiotics in accordance with regulations and with a valid prescription [30]. A study in Sri Lanka shows that $61 \%$ of pharmacies dispensed antibiotics without a prescription [44]. Another study found that most pharmacists do not have adequate knowledge about medicines in LMIC [45]. Thus continuing education on rational use of antimicrobial agents should be strengthened.

Forth, policy-makers should issue relevant antibiotic guidelines. Introduction and antibiotic prescribing guidelines combining specialists' consultation can improve doctors' prescribing behaviour [24]. In addition, hospital should include special antibiotic committees. A research in Nigeria shows a high decision autonomy in antibiotic prescribing in hospitals, which needs hospital Drugs and Therapeutic Committee (DTC) [39].

With regard to the current situation in Mali, the management of antibiotics still has a long way to go. The outbreak of Covid-19 although quite limited in Mali with total reported cases of 3706 by Nov.9th. has led to increased use of antibiotics. These patients are more likely to be prescribed broad spectrum antibiotics which more readily lead to bacterial in resistance. This study has some limitations. First, the sample was medical students in the only public medical school in Mali. Further studies need to include doctors, pharmacists, and the general population in Mali and in other neighboring countries. Second, self-report of behaviour is inevitably subject to social desirability bias, challenging validity. However, the high response rate helped to strengthen the validity of the results. Third, causality of variables cannot be inferred fromcross-sectional study design

\section{Conclusion}

Medical students in Mali have poor knowledge of antibiotics and overuse them for their own self-limiting illnesses. There is clear need to improved medical education on the antibiotic prescribing warnings against self-use, and the dangers of antimicrobial resistance. Raising awareness in the general public is also of great importance. 


\section{Funding}

This paper was funded by China Medical Board.

\section{Declaration of interest}

The authors have no relevant affiliations or financial involvement with any organization or entity with a financial interest in or financial conflict with the subject matter or materials discussed in the manuscript. This includes employment, consultancies, honoraria, stock ownership or options, expert testimony, grants or patents received or pending, or royalties.

\section{Author Contributions}

JC, A M S, XH S, KD, AM and TH made substantial contributions to conception and design, or acquisition of data. JC, YX and TH are also in charge of analysis and interpretation of data and the drafting of the paper and revising it critically for intellectual content.

\section{Acknowledgement}

The authors are very grateful to those students who participated amidst their extremely busy schedule. We also thank the Chinese Medical Team at the Mali hospital in Bamako for their support and hospitality. 
Table 1 Sociodemographic characteristics of

\begin{tabular}{lr} 
Malien students included in the study $(\mathrm{n}=446)$ \\
\hline Characteristic & $\mathrm{n}(\%)$ \\
\hline Age (years) (mean \pm S.D.) & $21.3 \pm 2.4$ \\
Gender & \\
Male & $310(69.5 \%)$ \\
Female & $136(30.5 \%)$ \\
Religion & \\
Islam & $398(89.2 \%)$ \\
Christianity & $46(10.3 \%)$ \\
Others & $2(0.4 \%)$ \\
Marital status & \\
Single & $404(90.6 \%)$ \\
Married & $33(7.4 \%)$ \\
Others & $9(2.0 \%)$ \\
Family income monthly(FCFA) & \\
$<100,000$ (US\$169) & $290(65.0 \%)$ \\
100,000-500,000 (US\$169-844) & $114(25.6 \%)$ \\
$>500,000$ (US\$844) & $42(9.4 \%)$ \\
Grade & \\
1st+2nd & $285(63.9 \%)$ \\
3rd-7th & $161(36.1 \%)$ \\
Home town & \\
Urban & $292(65.5 \%)$ \\
Rural & $154(34.5 \%)$ \\
\hline
\end{tabular}


Table 2. Knowledge related to antibiotic use of medical university students $(n=446)$.

\begin{tabular}{|c|c|c|c|}
\hline \multirow{2}{*}{ Questions } & \multicolumn{3}{|c|}{ Answers $[\mathrm{n}(\%)]$} \\
\hline & Yes & No & I don't know \\
\hline Antibiotics are effective for viral infections. & $195(43.7 \%)$ & $178(39.9 \%)$ & $73(16.4 \%)$ \\
\hline Antibiotics are effective for the flu. & $221(49.6 \%)$ & $143(32.1 \%)$ & $82(18.4 \%)$ \\
\hline Antibiotics are effective for the sore throat. & $278(62.3 \%)$ & $88(19.7 \%)$ & $80(17.9 \%)$ \\
\hline Antibiotics are effective for common diarrhea. & $239(53.6 \%)$ & $121(27.1 \%)$ & $86(19.3 \%)$ \\
\hline Antibiotics are the same as anti-inflammatory drugs. & $83(18.6 \%)$ & $311(69.7 \%)$ & $52(11.7 \%)$ \\
\hline We will have few antibiotics to use in the future if we don't use antibiotics properly. & $257(57.6 \%)$ & $111(24.9 \%)$ & $78(17.5 \%)$ \\
\hline The more frequently people use antibiotics, the more difficult it will be to treat bacterial infections. & $275(61.7 \%)$ & $129(28.9 \%)$ & $42(9.4 \%)$ \\
\hline Newer antibiotics are always more effective than older ones. & $321(72.0 \%)$ & $49(11.0 \%)$ & $76(17.0 \%)$ \\
\hline Infusion is the best way to give antibiotics. & $193(43.3 \%)$ & $181(40.6 \%)$ & $72(16.1 \%)$ \\
\hline Antibiotics might cause allergy leading to death. & $233(52.2 \%)$ & $123(27.6 \%)$ & $90(20.2 \%)$ \\
\hline
\end{tabular}


Table 3 Association between sociodemographic characteristics and health seeking behavior use in the past year.

\begin{tabular}{|c|c|c|c|c|c|c|c|c|c|c|c|c|c|}
\hline Characteristic & $\mathrm{n}$ & $\begin{array}{l}\text { Kept antibiotics } \\
\text { home/dorm(n=272) }\end{array}$ & at & $\mathrm{p}$ & $\begin{array}{l}\text { Self-limited } \\
\text { disease }(\mathrm{n}=391) \\
\text { p-value }\end{array}$ & $\begin{array}{l}\text { Went to see a } \\
\text { doctor(n=197) }\end{array}$ & $\mathrm{p}$ & $\begin{array}{l}\text { Prescribed with } \\
\text { antibiotics(n=160) }\end{array}$ & $\mathrm{p}$ & $\begin{array}{l}\text { Self-treated } \\
(\mathrm{n}=151)\end{array}$ & $\mathrm{p}$ & $\begin{array}{l}\text { Self-treated } \\
\text { with } \\
\text { antibiotics(n=12 } \\
\text { 1) }\end{array}$ & $\mathrm{p}$ \\
\hline Gender & & & & 0.29 & & & 0.27 & & 0.19 & & 0.22 & & 0.29 \\
\hline Male & 310 & $184(59.4 \%)$ & & & $268(68.5 \%)$ & $130(48.5 \%)$ & & $109(83.8 \%)$ & & $109(40.7 \%)$ & & $85(78.0 \%)$ & \\
\hline Female & 136 & $88(64.7 \%)$ & & & $123(31.5 \%)$ & $67(54.5 \%)$ & & $51(76.1 \%)$ & & $42(34.1 \%)$ & & $36(85.7 \%)$ & \\
\hline Religion & & & & 0.90 & & & 0.019 & & 0.77 & & 0.012 & & 0.022 \\
\hline Islam & 398 & $244(61.3 \%)$ & & & $346(88.5 \%)$ & $181(52.3 \%)$ & & $147(81.2 \%)$ & & $126(36.4 \%)$ & & $101(80.2 \%)$ & \\
\hline Christianity & 46 & $27(58.7 \%)$ & & & $43(11.0 \%)$ & $14(32.6 \%)$ & & $11(78.6 \%)$ & & $25(58.1 \%)$ & & $20(80.0 \%)$ & \\
\hline Others & 2 & $1(50.0 \%)$ & & & $2(0.5 \%)$ & $2(100.0 \%)$ & & $2(100.0 \%)$ & & $0(0.0 \%)$ & & $0(0.0 \%)$ & \\
\hline Marital status & & & & 0.15 & & & 0.33 & & 0.98 & & 0.23 & & 0.87 \\
\hline Single & 404 & $252(62.4 \%)$ & & & $355(90.8 \%)$ & $180(50.7 \%)$ & & $146(81.1 \%)$ & & $136(38.3 \%)$ & & $109(80.1 \%)$ & \\
\hline Married & 33 & $15(45.5 \%)$ & & & $29(7.4 \%)$ & $12(41.4 \%)$ & & $10(83.3 \%)$ & & $14(48.3 \%)$ & & $11(78.6 \%)$ & \\
\hline Others & 9 & $5(55.6 \%)$ & & & $7(1.8 \%)$ & $5(71.4 \%)$ & & $4(80.0 \%)$ & & $1(14.3 \%)$ & & $1(100.0 \%)$ & \\
\hline Family income & & & & 0.18 & & & 0.08 & & 0.59 & & 0.053 & & 0.41 \\
\hline $100,000 /$ month & 290 & $168(57.9 \%)$ & & & $251(64.2 \%)$ & $123(49.0 \%)$ & & $100(81.3 \%)$ & & $94(37.5 \%)$ & & $73(77.7 \%)$ & \\
\hline $100,000-$ & 114 & $77(67.5 \%)$ & & & $103(26.3 \%)$ & $60(58.3 \%)$ & & $50(83.3 \%)$ & & $36(35.0 \%)$ & & $29(80.6 \%)$ & \\
\hline \multicolumn{14}{|l|}{$500,000 /$ month } \\
\hline$>500,000 /$ month & 42 & $27(64.3 \%)$ & & & $37(9.5 \%)$ & $14(37.8 \%)$ & & $10(71.4 \%)$ & & $21(56.8)$ & & $19(90.5 \%)$ & \\
\hline Grade & & & & 0.07 & & & $<0.001$ & & 0.001 & & $<0.001$ & & 0.08 \\
\hline $1 \mathrm{st}+2 \mathrm{nd}$ & 285 & $165(57.9 \%)$ & & & $249(63.7 \%)$ & $145(58.2 \%)$ & & $110(75.9 \%)$ & & $79(31.7 \%)$ & & $59(74.7 \%)$ & \\
\hline
\end{tabular}




\begin{tabular}{|c|c|c|c|c|c|c|c|c|c|c|c|c|}
\hline 3 rd-7th & 161 & $107(66.5 \%)$ & & $142(36.3 \%)$ & $52(36.6 \%)$ & & $50(96.2 \%)$ & & $72(50.7 \%)$ & & $62(86.1 \%)$ & \\
\hline Home town & & & 0.85 & & & 0.92 & & 0.71 & & 0.92 & & 0.82 \\
\hline Urban & 292 & $179(61.3 \%)$ & & $255(65.2 \%)$ & $128(50.2 \%)$ & & $103(80.5 \%)$ & & $98(38.4 \%)$ & & $78(79.6 \%)$ & \\
\hline Rural & 154 & $93(60.4 \%)$ & & $136(34.8 \%)$ & $69(50.7 \%)$ & & $57(82.6 \%)$ & & $53(39.0 \%)$ & & $43(81.1 \%)$ & \\
\hline Knowledge score & & & 0.90 & & & 0.66 & & 0.45 & & 0.67 & & 0.20 \\
\hline$<5$ & 258 & $158(61.2 \%)$ & & $228(58.3 \%)$ & $117(51.3 \%)$ & & $93(79.5 \%)$ & & $86(37.7 \%)$ & & $72(83.7 \%)$ & \\
\hline$\geq 5$ & 188 & $114(60.6 \%)$ & & $163(41.7 \%)$ & $80(49.1 \%)$ & & $67(83.8 \%)$ & & $65(39.9 \%)$ & & $49(75.4 \%)$ & \\
\hline
\end{tabular}


Fig. 1. Antibiotic use behaviors of Malian medical university students.

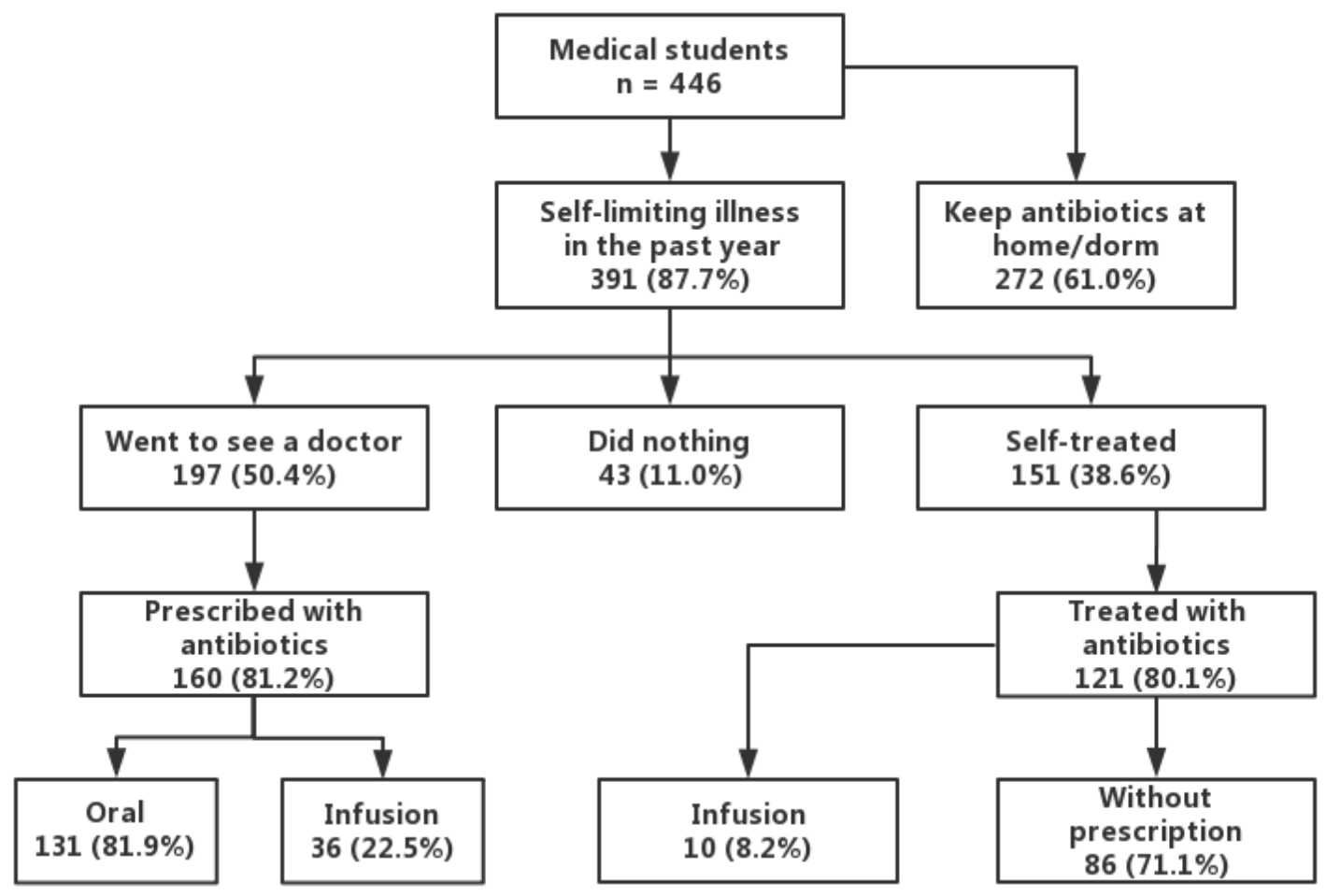




\section{References:}

* of interest

** of considerable interest

[1]. Mushtaq, A., UN commits to tackling antimicrobial resistance. Lancet Infect Dis, 2016. 16(11): p. 1229-1230.

*** This manuscript a good piece of work tackling antimicrobial resistance in a global view.

[2]. Gulland, A., World leaders pledge action on antimicrobial resistance. BMJ, 2016. 354: p. i5171.

[3]. J, O.N., Review on antimicrobial resistance: tackling a crisis for the health and wealth of Nations. 2014.

[4]. Klein, E.Y., et al., Global increase and geographic convergence in antibiotic consumption between 2000 and 2015. Proc Natl Acad Sci U S A, 2018. 115(15): p. E3463-E3470.

[5]. Mendelson, M., et al., Maximising access to achieve appropriate human antimicrobial use in lowincome and middle-income countries. Lancet, 2016. 387(10014): p. 188-98.

[6]. Sabtu, N., D.A. Enoch and N.M. Brown, Antibiotic resistance: what, why, where, when and how? Br Med Bull, 2015. 116: p. 105-13.

[7]. Rawson, T.M., et al., Bacterial and fungal co-infection in individuals with coronavirus: A rapid review to support COVID-19 antimicrobial prescribing. Clin Infect Dis, 2020.

[8]. Kost, G.J., Geospatial Spread of Antimicrobial Resistance, Bacterial and Fungal Threats to COVID-19 Survival, and Point-of-Care Solutions. Arch Pathol Lab Med, 2020.

[9]. Hsu, J., How covid-19 is accelerating the threat of antimicrobial resistance. BMJ, 2020. 369: p. m1983.

[10]. WHO, Record number of countries contribute data revealing disturbing rates of antimicrobial resistance. 2020 .

[11]. Currie, J., W. Lin and J. Meng, Addressing Antibiotic Abuse in China: An Experimental Audit Study. J Dev Econ, 2014. 110: p. 39-51.

[12]. Machowska, A. and L.C. Stålsby, Drivers of Irrational Use of Antibiotics in Europe. Int J Environ Res Public Health, 2018. 16(1).

[13]. Wang, H., et al., Prescription pattern and its influencing factors in Chinese county hospitals: a retrospective cross-sectional study. PLoS One, 2013. 8(5): p. e63225.

[14]. Babatola, A.O., et al., Addressing antimicrobial resistance in Nigerian hospitals: exploring physicians prescribing behavior, knowledge and perception of antimicrobial resistance and stewardship programs. Expert Rev Anti Infect Ther, 2020.

[15]. Fadare, J.O., et al., Drug promotional activities in Nigeria: impact on the prescribing patterns and practices of medical practitioners and the implications. Hosp Pract (1995), 2018. 46(2): p. 77-87.

[16]. Md, R.R., et al., Physicians' knowledge, perceptions and behaviour towards antibiotic prescribing: a systematic review of the literature. Expert Rev Anti Infect Ther, 2015. 13(5): p. 665-80.

[17]. Fadare, J.O., et al., Status of antimicrobial stewardship programmes in Nigerian tertiary healthcare 
facilities: Findings and implications. J Glob Antimicrob Resist, 2019. 17: p. 132-136.

[18]. Tillekeratne, L.G., et al., Antibiotic overuse for acute respiratory tract infections in Sri Lanka: a qualitative study of outpatients and their physicians. BMC Fam Pract, 2017. 18(1): p. 37.

[19]. Sekikubo, M., et al., Antibiotic Overconsumption in Pregnant Women With Urinary Tract Symptoms in Uganda. Clin Infect Dis, 2017. 65(4): p. 544-550.

[20]. Heaton, A., D.J. Webb and S.R. Maxwell, Undergraduate preparation for prescribing: the views of 2413 UK medical students and recent graduates. Br J Clin Pharmacol, 2008. 66(1): p. 128-34.

[21]. Kalungia, A.C., et al., Antimicrobial stewardship knowledge and perception among physicians and pharmacists at leading tertiary teaching hospitals in Zambia: implications for future policy and practice. J Chemother, 2019. 31(7-8): p. 378-387.

[22]. Burger, M., Knowledge and perceptions of antimicrobial stewardship concepts among final year pharmacy students in pharmacy schools across South Africa. 2016. 1(1): p. 1-7.

[23]. Wasserman, S., et al., South African medical students' perceptions and knowledge about antibiotic resistance and appropriate prescribing: Are we providing adequate training to future prescribers? S Afr Med J, 2017. 107(5): p. 405-410.

[24]. Bernabé, K.J., et al., Antimicrobial resistance in West Africa: a systematic review and metaanalysis. Int J Antimicrob Agents, 2017. 50(5): p. 629-639.

[25]. Moyimane, M.B., S.F. Matlala and M.P. Kekana, Experiences of nurses on the critical shortage of medical equipment at a rural district hospital in South Africa: a qualitative study. Pan Afr Med J, 2017. 28: p. 100.

[26]. WHO, Antimicrobial Resistance: Global Report on surveillance. 2014.

[27]. Niaz, Q., et al., Validity of World Health Organisation prescribing indicators in Namibia's primary healthcare: findings and implications. Int J Qual Health Care, 2019. 31(5): p. 338-345.

[28]. Nakwatumbah, S., et al., Compliance to guidelines for the prescribing of antibiotics in acute infections at Namibia's national referral hospital: a pilot study and the implications. Expert Rev Anti Infect Ther, 2017. 15(7): p. 713-721.

[29]. Godman, B., et al., Ongoing strategies to improve the management of upper respiratory tract infections and reduce inappropriate antibiotic use particularly among lower and middle-income countries: findings and implications for the future. Curr Med Res Opin, 2020. 36(2): p. 301-327.

[30]. Mali, C.E.I., Mali overview.

[31]. the World Federation for Medical Education and the Foundation for Advancement of International Medical Education and Research. (2016) the World Directory of Medical Schools. 2016.

[32]. Zawahir, S., S. Lekamwasam and P. Aslani, A cross-sectional national survey of community pharmacy staff: Knowledge and antibiotic provision. PLoS One, 2019. 14(4): p. e0215484.

[33]. Zakaa, E.M., et al., Egyptian community pharmacists' attitudes and practices towards antibiotic dispensing and antibiotic resistance; a cross-sectional survey in Greater Cairo. Curr Med Res Opin, 2019. 35(6): p. 939-946.

[34]. Wang, X.M., X.D. Zhou and T. Hesketh, Massive misuse of antibiotics by university students in China: a cross-sectional survey. Lancet, 2016. 388 Suppl 1: p. S94. 
** This a good piece KAP Study regarding Antibiotic Use in China.

[35]. Zhu, X., et al., Self-medication practices with antibiotics among Chinese university students. Public Health, 2016. 130: p. 78-83.

[36]. Haque, M., et al., A cross-sectional study evaluating the knowledge and beliefs about, and the use of antibiotics amongst Malaysian university students. Expert Rev Anti Infect Ther, 2019. 17(4): p. 275-284.

** A good piece KAP Study regarding Antibiotic Use in Malaysia.

[37]. Ocan, M., et al., Household antimicrobial self-medication: a systematic review and meta-analysis of the burden, risk factors and outcomes in developing countries. BMC Public Health, 2015. 15: p. 742 .

[38]. Donkor, E.S., et al., Self-medication practices with antibiotics among tertiary level students in Accra, Ghana: a cross-sectional study. Int J Environ Res Public Health, 2012. 9(10): p. 3519-29. [39]. Demoré, B., et al., Public knowledge and behaviours concerning antibiotic use and resistance in France: a cross-sectional survey. Infection, 2017. 45(4): p. 513-520.

[40]. Maïga, F.I., et al., Public and private sector responses to essential drugs policies: a multilevel analysis of drug prescription and selling practices in Mali. Soc Sci Med, 2003. 57(5): p. 937-48.

[41]. Goff, D.A., et al., A global call from five countries to collaborate in antibiotic stewardship: united we succeed, divided we might fail. Lancet Infect Dis, 2017. 17(2): p. e56-e63.

[42]. Kotwani, A., et al., Factors influencing primary care physicians to prescribe antibiotics in Delhi India. Fam Pract, 2010. 27(6): p. 684-90.

[43]. Neumark, T., L. Brudin and S. Mölstad, Antibiotic prescribing in primary care by international medical graduates and graduates from Swedish medical schools. Fam Pract, 2015. 32(3): p. 343-7. [44]. Zawahir, S., S. Lekamwasam and P. Aslani, Antibiotic dispensing practice in community pharmacies: A simulated client study. Res Social Adm Pharm, 2019. 15(5): p. 584-590.

** A good collection of documentation of current epidemiology and management of URTIs, particularly in LMICs.

[45]. Sakeena, M., A.A. Bennett and A.J. McLachlan, Non-prescription sales of antimicrobial agents at community pharmacies in developing countries: a systematic review. Int J Antimicrob Agents, 2018. 52(6): p. 771-782. 